\title{
Campos e núcleos de intervenção na terapia ocupacional social ${ }^{*}$
}

\author{
Intervention fields and cores in \\ social occupational therapy
}

\author{
Ana Paula Serrata Malfitano ${ }^{1}$
}

MALFITANO, A. P. S. Campos e núcleos de intervenção na terapia ocupacional social. Rev. Ter. Ocup. Univ. São Paulo, v. 16, n. 1, p. 1-8, jan./abr., 2005.

\begin{abstract}
RESUMO: O presente trabalho discute o papel profissional do terapeuta ocupacional enquanto técnico em atuação no campo social. Apresenta-se um breve histórico da terapia ocupacional nesta área e a demanda atual de sua inserção e desenvolvimento de projetos, para os quais defende-se uma intervenção calcada nos conceitos de autonomia, cidadania e direito. Compreende-se o campo social enquanto uma área interdisciplinar e intersetorial que pauta para diversas categorias profissionais, dentre elas para os terapeutas ocupacionais, a necessidade de aprimoramento de reflexões e metodologias para que se criem e/ou se fortaleçam as redes pessoais e sociais de suporte de pessoas e comunidades, população-alvo de tais intervenções. Defende-se que as diretrizes implantadas direcionem-se para o conceito de trabalho em equipe e constituição de rede, estruturada em diferentes níveis de assistência. Trabalha-se a partir dos conceitos de campo e núcleos de saberes, entendendo-se o campo enquanto um espaço interdisciplinar de atividades comuns e o núcleo como centro específico de cada profissional. O desafio encontra-se na necessária junção entre intervenção técnica e política, tarefa constante no campo, bem como na soma que redefine as contribuições dos diferentes núcleos presentes. $\mathrm{O}$ terapeuta ocupacional intervém no campo e também disponibiliza as especificidades nucleares da terapia ocupacional - a partir do uso da atividade e da mediação para compreensão destas como meio e não 'apenas' fim. Discute-se, nesse contexto, o papel profissional do terapeuta ocupacional no campo social.
\end{abstract}

DESCRITORES: Terapia ocupacional/tendências. Terapia ocupacional/história. Papel profissional. Estudos de informação. Planejamento em saúde comunitária. Redes comunitárias. Desinstitucionalização. Organização comunitária. Relações comunidade-instituição.

"Este artigo é um dos desdobramentos da dissertação "Políticas públicas e movimentos sociais: atenção à infância e o Programa de Saúde
da Família", defendida na Faculdade de Educaça da Universidade Estadual de Campinas - UNICAMP.
(1) Mestre em Educação pela Universidade Estadual de Campinas - UNICAMP. Terapeuta Ocupacional do Projeto Metuia. Terapeuta
Ocupacional atuando para a Prefeitura Municipal de Campinas.
Endereço para correspondência: R. Culto à Ciência, n. 293, ap.71. Botafogo. CEP: 13020-060. Campinas, SP. e-mail: amalfitano@uol.com.br 


\section{INTRODUÇÃO}

A s reflexões aqui apresentadas nascem da conjunção de experiências terapêuticoocupacionais acumuladas nos últimos anos no campo social, principalmente direcionada às crianças e aos adolescentes, bem como da sistematização de tais reflexões no interior do Projeto Metuia ${ }^{(1)}$ e debatidas na forma de dissertação e artigos.

Nossa dissertação referenciou-se em um trabalho de campo qualitativo, realizado no período de 1999 a 2003, a partir dos procedimentos metodológicos baseados na Pesquisa Participante, na observação participante e em entrevistas com atores locais (MALFITANO, 2004). Nesta ocasião tivemos a oportunidade de entrevistar terapeutas ocupacionais em intervenção no campo social a partir de um projeto em parceria entre a associação de moradores locais e Universidades (BARROS et al., 1999), ofertandonos elementos nos quais baseamos as reflexões que aqui seguem. Esta discussão não foi objeto central da dissertação em questão, porém apresentamos seus desdobramentos por considerar o tema de grande relevância, principalmente para o diálogo com os profissionais da área.

Considerando a situação de precariedade e vulnerabilidades extremas de grande parcela da população brasileira na sociedade contemporânea, principalmente em grandes centros urbanos (SPOZATI, 2001), torna-se um desafio para os profissionais, entre eles o terapeuta ocupacional, criar metodologias, reflexões e estratégias de intervenção para atuação no campo social.

Apoiamo-nos nos conceitos ofertados por Castel (1994, 1997), que compreende as redes sociais e pessoais de suporte como elementos fundamentais na definição de maior ou menor vulnerabilidade daquele que tem uma integração precária ao mundo do trabalho, como elementos que podem impedir o que esse autor denomina de desfiliação. Para Castel (1994), a inserção deve ser analisada a partir de dois eixos: o da relação de trabalho (com uma gama de posições, do emprego estável à ausência completa de trabalho) e o da inserção relacional (entre a inscrição nas redes sólidas de sociabilidade e o isolamento social total). $\mathrm{O}$ recorte desses dois eixos circunscreve zonas diferentes do espaço social: zona de integração - onde se dispõe de garantias de um trabalho permanente e pode-se mobilizar suportes relacionais sólidos; zona de desfiliação - onde se conjuga ausência de trabalho e isolamento social, implicando uma dupla ruptura das redes de sociabilidade e participação; zona de vulnerabilidade - que associa precariedade do trabalho e fragilidade relacional.

A atuação no campo social prevê projetos que se dediquem a criar e/ou fortalecer tais redes sociais de suporte, no âmbito individual e coletivo, a partir do contexto microssocial que o sujeito está envolvido, realizando o trilhar sempre constante com a macroestrutura presente.

\section{Terapia Ocupacional no Campo Social}

A terapia ocupacional conhece as primeiras discussões a respeito da intervenção no campo social durante a década de 1970, momento em que os movimentos sociais passaram a articular proposições sobre o Estado, a sociedade civil e os seus respectivos papéis, sendo que alguns profissionais, atentos a estes movimentos, desenvolveram a reflexão sobre sua função político-social (BARROS et al., 2002a).

Acompanhando a dinâmica dos movimentos sociais inicia-se um relevante debate sobre os processos de desinstitucionalização, principalmente no campo da saúde mental. Os terapeutas ocupacionais passaram a integrar tais discussões uma vez que realizavam ações no interior das instituições totais, exercendo um papel definido por Galheigo (1997) como o de "promotores de adaptação social".

A desinstitucionalização, acompanhada de intervenções no âmbito territorial, impulsiona o repensar a prática profissional e insere o eixo da cidadania na composição do escopo da visão do terapeuta ocupacional.

Esta nova proposição espera que o profissional rompa os limites estabelecidos pelos muros da instituição, que acesse o usuário em seu território, que promova ações para além dos limites institucionais. A noção de território aqui considerada baseia-se não só na delimitação geográfica de uma região, mas pressupõe também sua constituição histórica e as relações socioeconômicas e culturais ali desenvolvidas (OLIVER; BARROS, 1999).

Nele [o território] pode-se observar diferentes maneiras de existir, sonhar, viver, trabalhar e realizar trocas sociais. Essa noção exige que se tenha a compreensão de intervenção em saúde que supere a noção de risco, que isola e escolhe determinadas variáveis, geralmente de ordem

\footnotetext{
(1) "Grupo interinstitucional de estudos, formação e ações pela cidadania de crianças, adolescentes e adultos em processo de ruptura das redes sociais de suporte, formado por docentes, discente e profissionais da área de terapia ocupacional ligados às universidades: Pontifícia Universidade Caólicacecampirs PUCGAMPINAS), Universidade Federal de São Carlos (UFSCar) e Universidade de São Paulo (USP)" (BARROS et al., 2002b, p.365).
} 
biológica, para o desenvolvimento das ações de saúde. A intervenção em saúde deve estar pautada pela noção de chances de vida, que busca trabalhar a partir de uma visão do ambiente ecológico e social em que estas vidas se tecem. Dessa maneira entende-se que as chances de vida determinam as chances de saúde das pessoas (BARROS et al., 2002a, p. 100).

A contextualização territorial traz outros âmbitos para o desenvolvimento do trabalho, possibilitando que o processo proposto pela terapia ocupacional possa ser ampliado para a construção de novas abordagens, para a utilização de novos espaços, para as dimensões macroestruturais, co-relacionando aspectos que na prática não se isolam, são permeados uns pelo outros.

Nessa direção, na saúde coletiva se coloca o debate sobre a construção de uma "clínica ampliada", a busca do protagonismo do sujeito, e não apenas da doença, do território em que está inserido, ampliando o setting terapêutico, em prol de uma clínica do sujeito (CAMPOS, 2001). Desenvolve-se a compreensão de que o trabalho profissional não deve se restringir a uma clínica tradicional protegida pela instituição. Pauta-se a necessidade de ir ao encontro do sujeito, promover seu acesso aos serviços, realizar abordagens que sejam contextualizadas em sua realidade, história e cultura, criando novas formas de produção de saúde.

Para a construção desta clínica do sujeito faz-se necessário tecer o trânsito entre o individual e o coletivo, assim como entre o institucional e o político. É na promoção desta articulação que se encontra a complementaridade indissociável entre os aspectos que influenciam a vida do sujeito.

Debate-se também a contribuição das diversas áreas de atuação para a composição do campo social. No campo da saúde questiona-se quais contribuições serão dadas para a busca de respostas aos problemas da sociedade contemporânea, como a violência, o uso abusivo de substâncias psicoativas, o desenvolvimento de crianças e adolescentes nas ruas, dentre tantos outros exemplos. Para tais questões, não basta a produção de dados epidemiológicos, o tratamento clínico ambulatorial e as internações. Desafiam-nos a criação de novas formas de abordagem e 'tratamentos' que não se encerram na clínica e que demandam a ampliação e criação de novas metodologias.
Na educação discute-se os limites da educação formal e os procedimentos excludentes adotados pela escola; na área da educação não-formal tenciona-se para que se supere o modelo de escolarização complementar (GARCIA, 2003).

Já para a assistência social, historicamente relacionada a ações coletivas de caráter compensatório (MESTRINER, 2001), aponta-se o questionamento da necessária inserção do sujeito individual, numa abordagem à família que supere as formas tradicionais, podendo ampliar a abordagem sistêmica.

No campo da justiça espera-se a real promoção dos direitos de forma igualitária.

$\mathrm{Na}$ área da cultura as atividades culturais podem assumir um caráter de promoção de lazer e não apenas de formação e divulgação profissional de artistas.

Nesse contexto, o trabalho permanece como categoria central sendo a geração alternativa de renda ainda um desafio para o estabelecimento de uma economia solidária (SINGER; SOUZA, 2000) que também seja voltada para lidar com as diferenças (GHIRARDI, 2004) ${ }^{(2)}$.

Portanto, a constituição de intervenções no campo social é composta por uma diversidade de áreas que têm internamente discussões a realizar para ofertar as suas contribuições. O terapeuta ocupacional, ao ingressar neste campo, apresenta limites e possibilidades e deve debater alguns pontos chave de sua atuação, tais como: os limites da clínica, as possibilidades da promoção da convivência, o caminhar entre o individual e o coletivo e entre o técnico e o político.

O terapeuta ocupacional tem uma capacidade de articular o macro e o micro, ele se propõe a falar de ações territoriais (...) está no contato com as pessoas, no cotidiano, no dia-adia. Acredito que nossa história, por vir da saúde, ou por vir de um cuidado mais individual, permite que façamos a articulação entre o coletivo e o individual, que talvez outros profissionais não façam (...). A discussão da ação no território, no contexto social, no bairro, na comunidade, articulado a proposições de mudança, de ação, de pautar é importante. O terapeuta ocupacional propõe esta composição de articulação da ação coletiva e da individual, do macro e do micro (...) podendo também contextualizar uma abordagem indivi-

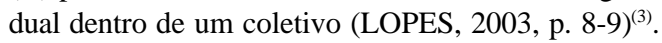

Neste campo, o profissional é chamado, para além do desenvolvimento do trabalho individual e institucional, para

\footnotetext{
(2) GHIRARDI, M. I. Terapia ocupacional e as fronteiras de seu território. Palestra proferida no II Simpósio Paulista de Terapia Ocupacional. Campos do Jordão, SP, 29 ago 2004.

(3) LOPES, R. E. Comunicação pessoal. Professora Adjunta do Departamento de Terapia Ocupacional e do Programa de Pós-Graduação em Educação da Universidade Federal de São Carlos, Coordenadora do Projeto Metuia. 24 nov. 2003, 9p.
} 
assumir também um papel de articulador social, sendo sua demanda a reflexão e produção de intervenções que estejam relacionadas ao domínio "macro-estrutural e conceitual, o político-operacional e o da atenção pessoal e coletiva" (GALHEIGO, 1999, p. 24).

Pensar políticas públicas, conhecer leis específicas do grupo populacional com quem se está intervindo, construir propostas, atuar no âmbito público, passam a ser demandas de trabalho para o terapeuta ocupacional.

Enfatiza-se, portanto, a necessária incorporação do aspecto político no cotidiano do trabalho profissional, compreendendo-o como uma demanda que deve fazer parte integrante das tarefas diárias. O profissional precisa estabelecer um diálogo entre a microestrutura - seu cotidiano de ações com sua população-alvo - e a macroestrutura - no aspecto das políticas sociais articulando uma política que viabilize o acesso aos direitos para esta população.

\section{Campos e núcleos de intervenção}

O campo social implica em uma gama de ações que apresentam uma diversidade de núcleos a serem desenvolvidos por diferentes saberes, compondo um espaço que envolve dois âmbitos de atuação. $\mathrm{O}$ primeiro, que denominamos de campo, com um caráter mais geral e interdisciplinar, envolve diferentes atores; o segundo é composto por núcleos específicos nos quais se encontram a atuação de uma dada área, com um dado profissional, dentro de uma certa especificidade.

Campos (2000) desenvolve a idéia de campo e núcleo de saberes ao discorrer sobre a saúde pública e suas interfaces. A partir dos mesmos princípios, compreendemos o campo social enquanto esfera interdisciplinar com interfaces com diversos núcleos, cujos projetos exigem a intervenção, a comunicação e o trabalho conjunto entre os diferentes atores para composição de uma rede de intervenção.

Não se trata de priorizar o campo ou algum núcleo, temse estes diferentes componentes atuando em um mesmo contexto, demandando ações realizadas em rede que se traduzam numa maior efetividade para a população atendida.

Propomos na Figura 1 a visualização gráfica daquilo que compreendemos enquanto intervenções no campo social contendo alguns dos núcleos que o compõem, ressaltando a não completude do gráfico. Este campo de ação prevê uma gama de intervenções, individuais e coletivas, direcionadas para a promoção do direito e da cidadania, e que buscam viabilizar aquilo que o sujeito deseja, necessita e/ou possibilitar a ampliação de vivências e repertórios sócioculturais para a sua vida.

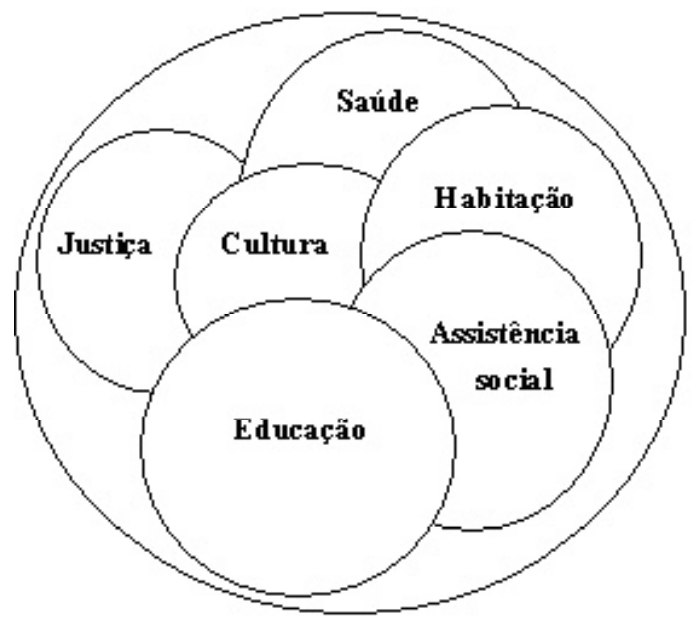

Figura 1 - Campo social e núcleos de saberes

No nível da macroestrutura são também esperados "trabalhos" no campo social, tais como: as ações de coordenação de serviços e projetos, a discussão para a constituição de políticas sociais, a defesa de direitos, dentre outras. Espera-se que os profissionais possam contribuir com ações interdisciplinares efetivadas no campo, bem como desenvolver um trabalho em equipe e no contexto de uma rede de atendimento.

A comunicação e ação conjunta dos vários núcleos têmse denominado intersetorialidade, princípio que compreendemos como essencial para a realização de políticas, programas e projetos no campo social. Terapeutas ocupacionais que entrevistamos apontam a intersetorialidade enquanto o meio mais efetivo para o desenvolvimento de novas propostas de trabalho. Contudo, observa-se que a intersetorialidade se coloca ainda como proposição, como um indicativo futuro de diretriz, pois há pouco acúmulo de experiências e concretizações, o que limita o campo social a ações fragmentadas que não são interconectadas, diminuindo suas potencialidades e possibilidades.

A implementação de propostas de natureza intersetorial exige a discussão sobre financiamento e administração de equipamentos que comportem diferentes núcleos, que no poder público são representados por diferentes órgãos e secretarias, na proposição de uma atuação conjunta (LOPES, 2003) $)^{(4)}$.

\footnotetext{
(4) LOPES, R. E. Comunicação pessoal. Professora Adjunta do Departamento de Terapia Ocupacional e do Programa de Pós-Graduação em Educação da Universidade Federal de São Carlos, Coordenadora do Projeto Metuia. 24 nov. 2003, 9p.
} 
Exige também o debate sobre a integração da divisão dos saberes e a segmentação burocrática das intervenções públicas.

O cotidiano do trabalho mostra que as experiências que buscam a ampliação do leque de atuação, não se restringindo apenas a um núcleo de saber, têm a dificuldade de sua compreensão e responsabilização pelo poder público, o que limita suas possibilidades.

Deve-se notar também, no contexto neoliberal, o enxugamento de gastos sociais em prol de um Estado interventor mínimo. Nessa lógica, os escassos recursos públicos existentes são direcionados para situações emergenciais, compondo ações isoladas, descontextualizadas, desconectadas do campo social na qual estão inseridas (DRAIBE, 1993).

Investe-se "apenas" - sublinhando este "apenas" por se tratar de intervenções relevantes e necessárias - no trabalho com problemáticas caracterizadas pelo agravamento da situação social, que demonstram a ausência do Estado naquilo que deveria ser garantido para os seus cidadãos. Exemplo disso são as ações destinadas a crianças e adolescentes, as consequiências da violência doméstica, aos adolescentes infratores, as crianças e jovens em situação de rua, à exploração sexual etc.

Assim, não se visualiza uma política pública de cuidado que se organize em diferentes níveis de atenção e ofereça assistência efetiva na área social. Depara-se com um campo desenraizado e fragmentado direcionado para intervenções que são, na maioria dos casos, ações compensatórias, não se configurando em um 'nível primário de intervenção'. Geralmente os projetos direcionados a grupos populares não são desenvolvidos com um caráter público, assim como não são enquadrados como direito de cidadania.

Investe-se precariamente nas situações emergenciais quando a população se encontra já no campo da desfiliação, sem realizar propostas para a mesma quando esta se encontra na zona de vulnerabilidade social, buscando auxiliá-la para que a transposição dentre estas porosas zonas não venha a se efetivar.

Contudo, o campo social apresenta desafios para os profissionais que atuam neste escopo. Trata-se de intervir num campo interdisciplinar e intersetorial que requer ações políticas que o fortaleça, pautando-o como prioritário para intervenção, realizando ações comuns e socializando-as com os demais profissionais presentes, bem como criando métodos nucleares com a população para a qual se destina o trabalho.

\section{Terapia Ocupacional: contribuições do núcleo na proposição do trabalho no campo social}

Para a discussão do núcleo de intervenção da terapia ocupacional no campo social, partimos do princípio de que suas ações buscam a autonomia e cidadania do sujeito, interferindo em seu cotidiano para promoção de mudanças.

A terapia ocupacional é um campo de conhecimento e intervenção em saúde, em educação e na ação social, que reúne tecnologias orientadas para a emancipação e a autonomia de pessoas que, por razões ligadas a problemáticas específicas (físicas, sensoriais, psicológicas, mentais e/ou sociais), apresentam, temporária ou definitivamente, dificuldades de inserção e participação na vida social (BARROS et al., 2002b, p. 366).

Para que se efetive o trabalho do núcleo da terapia ocupacional no campo social parte-se do princípio de que é necessário que haja o reconhecimento do outro como interlocutor do processo e que se promova:

1. descentramento do saber do técnico para a idéia de saberes plurais diante de problemas e de questões sociais;

2. descentramento das ações da pessoa (considerada corpo / mente doente ou desviante) para o coletivo, a cultura da qual a pessoa não pode ser separada;

3. descentramento da ação: do enquadramento (setting) para os espaços de vida cotidiana;

4. descentramento do conceito de atividade como processo individual para inseri-lo na história e cultura de um grupo ou de uma pessoa (BARROS, 2002a, p. 100).

O uso da atividade enquanto recurso terapêutico é um instrumento de trabalho historicamente utilizado pela terapia ocupacional com diferentes grupos populacionais. No campo social, principalmente em trabalho direcionados para crianças e adolescentes, o recurso grupal, através de oficinas artísticas e/ou culturais, é utilizado enquanto elemento constante para efetivação do trabalho.

Em grande parte dos projetos sociais não encontramos a presença do terapeuta ocupacional compondo as equipes de trabalho. Cabe a este profissional, a partir das oportunidades que lhe são ofertadas, apresentar suas contribuições, apontando o uso de seus recursos enquanto elemento meio, que visam o fim de produção de autonomia, configurando assim seu instrumental de intervenção, colocando o uso de atividades enquanto ações relevantes para intervenções que se inserem em um campo interdisciplinar. 
Partindo-se da concepção da atividade enquanto meio de formação de vínculo, aproximação, intermediação para que se possa iniciar a construção conjunta de novos projetos de vida; interpreta-se tais abordagens enquanto núcleo de ação do terapeuta ocupacional.

\begin{abstract}
Você precisa de profissionais que consigam transitar entre o que é uma oficina de capoeira e o que é expressão de descontentamento, de revolta, ou de um mau comportamento, ou um comportamento esquivo que apareça nos grupos; e o que é que essa pessoa, essa criança, esse jovem está dizendo? O que é o mundo dela na esfera do trabalho e da família? E poder pensar essa oficina cultural, por exemplo, na relação com o conjunto daquilo que ela é, do que ela vive, das possibilidades e impossibilidades que ela têm, então nesse sentido acho que o terapeuta ocupacional seria de grande valia porque ele pode ser este elo, saber ler os símbolos daquilo que é a atividade de capoeira e compreender aquilo que é a representação e a valorização desta atividade por quem a freqüenta, e colocar essas duas coisas, ou essas duas instâncias, no conjunto da vida e, sobretudo, das dificuldades que eventualmente confluem para que ela não consiga produzir a sua autonomia mínima que se espera de uma pessoa na sociedade, a partir de sua idade (BARROS, 2003, p. 5-6).
\end{abstract}

O terapeuta ocupacional dedica-se a uma leitura do cotidiano e seus contextos, a intermediação entre a estrutura macro e microssocial, a ressignificação do fazer, a intervenção individual e coletiva, desenvolvendo estratégias que buscam o fortalecimento das redes pessoais e sociais de suporte, com o objetivo de que essas venham a se traduzir em uma maior sustentabilidade autônoma do sujeito na complexa estrutura social em que está inserido (GALHEIGO, 2003; BARROS et al., 2002a).

Compreendemos, portanto, que o terapeuta ocupacional é um dos profissionais que compõem, a partir do seu núcleo de saber, o campo social, demandando para a efetividade de seu trabalho a atuação entrelaçada com outros profissionais, a partir de uma concepção intersetorial.

\section{CONSIDERAÇÕES FINAIS}

Em nossa visão, o campo social é um campo interdisciplinar e intersetorial que demanda, enquanto função social dos profissionais na sociedade contemporânea, reflexões e intervenções que se dediquem à produção e/ou ao fortalecimento das redes sociais de suporte de grupos populacionais em situação de vulnerabilidade social, bem como em situação de desfiliação.
Para que se direcione os esforços no sentido de fomentar a produção das redes sociais de suporte é necessário que haja uma mudança de paradigmas, revisão de metodologias e abordagens, que reconheçam o campo social enquanto um complexo escopo que demanda a articulação de trabalhos. Pautamos algumas reflexões para as quais o terapeuta ocupacional pode dedicar-se enquanto profissional do campo social.

Os diversos núcleos profissionais apresentam diferentes limites para os quais se faz necessário a superação de paradigmas enraizados. Ressaltamos assim, dentre outras questões, a relevância do debate sobre os limites da clínica, as possibilidades de promoção da convivência, a indissociabilidade entre ação técnica e política e o trânsito sempre constante entre o individual e o coletivo, a macro e a microestrutura.

Contudo, a produção deste campo não deve estar restrita a discussão sobre o papel do técnico, mas também, e de forma extremamente relevante, a concepção e prática das políticas sociais.

As experiências que se observam não se encontram enraizadas em princípios interdisciplinares e intersetoriais, conforme citado acima, sendo, na maioria das vezes, projetos isolados e fragmentados tendo como diretriz única a dinâmica institucional na qual se inserem, afastando-se da proposição de formulação de uma política intersetorial.

Estas intervenções demonstram, em sua maioria, produção de resultados, podendo vir a criar modificações nas redes sociais de suporte de determinados grupos, sem a necessidade de alto investimento tecnológico e de recursos materiais, porém com uma ênfase pontual e focal. O grande investimento necessário centra-se na capacitação de recursos humanos que se responsabilizem pelo desenvolvimento de ações complexas, sendo necessário, para tanto, que estejam inseridos em projetos políticos diretivos que tenham, baseados na clareza e prioridade de políticas e gestores, os recursos necessários para a promoção de novos métodos no campo social.

Sendo assim, por se tratar de um campo interdisciplinar e, portanto, requerente de uma diversidade de ações técnicas e políticas e composta por núcleos de saberes entrelaçados que buscam a composição de um todo, assinalamos o papel do profissional da área de terapia ocupacional.

Por fim, destacamos que os profissionais que se dedicam à intervenção no campo social têm o desafio de articular ações de campo e núcleo, em um cotidiano de trabalho de grandes demandas, buscando novas formas 
de abordagens que inovem as já existentes, criando novas metodologias que fortaleçam significativamente as redes sociais de suporte da população em atendimento.

Apresentamos aqui o resultado do debate de uma prática dedicada ao campo social, que é composta por uma enormidade de desafios e questionamentos, que acreditamos ser o motor de impulsão para o desenvolvimento de intervenções técnicas, profissional, que se dediquem à promoção da autonomia e cidadania daqueles que se encontram destituídos de seus direitos.

MALFITANO, A. P. S. Intervention fields and cores in social Occupational Therapy. Rev. Ter. Ocup. Univ. São Paulo, v. 16, n. 1, p. 1-8, jan./abr., 2005.

\begin{abstract}
This work presents discuss on the occupational therapist professional role as a technician acting on the social field. A brief history of occupational therapist acting in this field and the present need for action insertion and projects' development, to which is presented an intervention based on the concepts of autonomy, citizenship and rights. The social field is understood as interdiscipline and intersection sphere which challenges reflexions and methodologies to many professional categories, as occupational therapist, to create and/or increase personal and supporting social nets from people and comunities, the population to whom the actions in the social field are targeted. The purpose is so that implanted directives target the concept of staff work and the build of a net for the social field - whcih structures in different levels of assistance. It works from the concepts of fields and knowledge cores, understanding field as an interdisciplinar activities sphere and the core as a center for specific actions from each professional. The challenge is in the necessary junction between technical and political intervention, tasks presents in the field, adding contributions from different cores. The occupational therapist acts in the field and also bid their specificity from the core of occupational therapy - from the activity and the comprehension of it as path activity, and not 'only' as the end. The occupational therapist's role in social field is discussed, in this context.
\end{abstract}

KEY WORDS: Occupational therapy/trends. Occupational therapy/history. Professional role. Intervention studies. Community health planning. Deinstitutionalization. Community networks. Communitarian organization. Community-institutional relations.

\title{
REFERÊNCIAS
}

BARROS, D. D.; GUIRARDI, M. I. G.; LOPES, R. E. Terapia CASTEL, R. As dinâmicas do processo de marginalização: da ocupacional social. Rev. Ter. Ocup. Univ. São Paulo, São Paulo, v. 13, vulnerabilidade à desfiliação. Cadernos CRH, Salvador, n. 26-7, n. 2, p. 95-103, 2002a. p. 19-40, 1997.

BARROS, D. D.; LOPES, R. E.; GALHEIGO, S. M. Projeto Metuia - CASTEL, R. Da indigência à exclusão, a desfiliação. terapia ocupacional no campo social. Mundo Saúde, São Paulo, v. 26, Precariedade do trabalho e vulnerabilidade relacional. In: n. 3, p. 365-369, 2002b.

LANCETTI, A. (Org.). Saúde loucura, n. 4. São Paulo: Hucitec, 1994. p. 21-48.

BARRoS, D. D. et al. Projeto Casarão: Centro de Cultura e Convivência Celso Garcia. Projeto Metuia - Núcleo USP/UFSCar. São Paulo, São Carlos, 1999. 20 p. Mimeografado.

DRAIBE, S. M. As políticas sociais e o neoliberalismo. Rev. USP, São Paulo, v. 13, p. 86-101, 1993.

CAMPOS, G. W. S. Saúde pública e saúde coletiva: campo e núcleo de saberes e práticas. Ciên. Saúde Coletiva, Rio de Janeiro, v. 5, n. 2, p. 219-230, 2000.

CAMPOS, R. O. Clínica: a palavra negada - sobre as práticas clínicas nos serviços substitutivos de Saúde Mental. Saúde Debate, Rio de Janeiro, v. 25, n. 58, p. 98-111, 2001.

GALHEIGO, S. M. O social: idas e vindas de um campo de ação em terapia ocupacional. In: PÁDUA, E. M. M.; MAGALHÃES, L. V. (Orgs.). Terapia ocupacional: teoria e prática. Campinas: Papirus, 2003, p. 29-46.

GALHEIGO, S. M. Repensando o lugar do social: a constituição de um campo de conhecimento em terapia ocupacional. In: 
Congresso Brasileiro de Terapia Ocupacional, 6., 1999, Águas de Lindóia. Programas e resumos. Águas de Lindóia, 1999. p. 24.

GALHEIGO, S. M. Da adaptação psico-social à construção do coletivo: a cidadania enquanto eixo. Rev. Ciên. Méd. PUCCAMP, Campinas, v. 6, n. 2/3, p. 105-108, 1997.

GARCIA, V. A. Educação não-formal: do histórico ao trabalho local. In: PARK, M. B. (Org.). Formação de educadores: memória, patrimônio e meio ambiente. Campinas: Mercado das Letras, 2003.

MALFITANO, A. P. S. Políticas públicas e movimentos sociais: atenção à infância e o Programa de Saúde da Família. 2004. 180 f. Dissertação (Mestrado em Educação)-Faculdade de
Educação, Universidade Estadual de Campinas, Campinas, 2004.

MESTRINER, M. L. O Estado entre a filantropia e a assistência social. São Paulo: Cortez, 2001.

OLIVER, F. C.; BARROS, D. D. Reflexionando sobre desinstitucionalización y terapia ocupacional. Materia Prima. Primera Rev. Independiente Ter. Ocup. Argentina, Argentina, v. 4, n. 13, p. 17-20, 1999.

SINGER, P.; SOUZA, A. R. A economia solidária no Brasil: a autogestão como resposta ao desemprego. São Paulo: Contexto, 2000.

SPOSATI, A. O. Cidade em pedaços. São Paulo: Brasiliense, 2001. 